Revista Iberoamericana, Vol. LXXV, Núm. 226, Enero-Marzo 2009, 191-204

\title{
SARMIENTO, DARÍO Y BORGES, O EL DILEMA DE LAS MODERNIDADES MARGINALES
}

\author{
POR \\ MARIANO SisKIND \\ Harvard University
}

1. El DESEO MOderno de AmÉRICA LATINA

La escena intelectual latinoamericana del siglo xIx nació atravesada por el deseo de la modernidad. Las elites criollas, cuya subjetividad burguesa se erigía en un espacio indecidible entre la presunta universalidad de la cultura europea y la particularidad de las tradiciones locales, estaban constituidas por el deseo de una modernidad americana que fuera capaz de conciliar esos dos polos en tensión. El deseo de modernidad era la intersección simbólica del proceso político de organización de territorios y poblaciones en estados nacionales, y de proyectos estéticos y culturales que buscaban, a la vez, la especificidad que reforzara la ruptura con España y un efecto modernizador que los colocara en el corazón de la historia universal, cuyos flujos globales emanaban desde París. París era para estas elites intelectuales el referente privilegiado alrededor del cual se articulaban simbólicamente los diferentes proyectos modernizadores. Pero estos discursos no aludían necesariamente a la materialidad específica de París o de la cultura francesa; se trataba más bien de la invocación de lo que Ernesto Laclau llama un significante vacío, al que los intelectuales latinoamericanos le asignaban el contenido de "Lo Moderno". En otras palabras, la construcción de París y la cultura francesa como encarnaciones de las premisas universales de la modernidad; París como concepto universal en relación con el que América Latina produciría su particularidad moderna.

En este artículo me propongo analizar dos momentos marcadamente diferentes dentro de esta genealogía del deseo moderno en el siglo xix: los modos en los que Domingo F. Sarmiento y Rubén Darío articulan sus ideas respecto de la posibilidad de construir una modernidad específicamente latinoamericana. A través de los conceptos de "modernidad mimética", en el caso de Sarmiento, y "modernidad traducida", en el de Darío, quisiera tratar de pensar el modo en el que los discursos sobre la modernidad en América Latina necesariamente se construyen en complejas relaciones de imitación, traducción, rechazo o apropiación subversiva de la expansión 
global de los discursos sobre la modernidad europeos y estadounidenses. Sobre el final, a modo de cierre, y casi como una coda, voy a referirme muy brevemente al modo en el que Borges reelabora las hipótesis de Sarmiento y Darío en el contexto del siglo xx, para así tratar de presentar una visión histórica, hacia una genealogía posible de la relación del deseo latinoamericano de la modernidad, en relación con discursos sobre la universalidad de lo moderno.

Mi hipótesis es que en América Latina -y en términos más generales, en los márgenes del universal moderno- el deseo de una modernidad latinoamericana se articula a partir de dos movimientos: 1) el reconocimiento de una especificidad latinoamericana en el teatro mundial de la modernidad, que es conceptualizada en términos de marginalidad; y 2) la articulación del deseo moderno con la pregunta por la identidad: Si nuestra situación histórica es evidentemente diferente de la de Francia, ¿cómo podemos ser modernos, cómo podemos construir una identidad moderna para América Latina? Formulada desde los márgenes del universal, la pregunta por la modernidad es una pregunta por la diferencia.

\section{EL DILEMA DE LAS MODERNIDADES MARGINALES}

Si el intelectual latinoamericano decimonónico percibe a París como la materialización perfecta de la modernidad, como un espacio único en su capacidad de cifrar la identidad de la particularidad francesa y la esencia universal de la modernidad, naturalmente concibe el viaje a la capital del siglo XIX como la posibilidad de la experiencia moderna que América Latina desea para sí. En función de la conciencia de la falta que constituye la condición enunciativa del intelectual latinoamericano, el viaje a Francia es vivido como la posibilidad de colmar ese vacío, como la experiencia de una plenitud de sentido que predeciblemente, tiene fuertes connotaciones religiosas. Dice Sarmiento en sus Viajes:

ahora que me aproximo a [Francia] aquel foco desde donde parten para nosotros movimientos del espíritu, uno en pos de otro, como los círculos concéntricos que describen las aguas agitadas en algún punto de la superficie, siento no sé qué timidez, mezcla de curiosidad, admiración y respeto, como aquel sentimiento religioso indefinido del niño que va a hacer su comunión primera. (83)

Más de medio siglo más tarde, Darío repite el gesto en su Autobiografía:

Yo soñaba con París desde niño, a punto de que cuando hacía mis oraciones rogaba a Dios que no me dejase morir sin conocer París. París era para mí como un paraíso en donde se respirase la esencia de la felicidad sobre la tierra... E iba yo a conocer París, a realizar la mayor ansia de mi vida. Y cuando en la estación de Saint-Lazaire pisé tierra parisiense, creí hallar suelo sagrado. (69) 
El viaje a París, entonces, baña al intelectual de la legitimidad que buscaba al emprender la travesía. La metáfora religiosa es absolutamente eficaz: París, en su divinidad secular, cubre de sentido a los discursos sobre la modernidad latinoamericana, del mismo modo que Dios inscribe en el caos asistemático del mundo un orden significante. En consecuencia, el intelectual ahora legitimado por su contacto directo con París se vuelve vate, poeta visionario, guía en el incierto proceso de modernización. Sin embargo, lo que me interesa del modo en el que Sarmiento y Darío conceptualizan sus respectivos viajes a París no es analizar el fenómeno textual y cultural del viaje (muchos críticos han analizado este corpus textual; entre otros: David Viñas, Angel Rama, Sylvia Molloy, Julio Ramos, Diana Sorensen, Paul Verdevoye y Beatriz Colombi). Lo que me interesa es que en camino a París, ya en París, o desde América Latina pensando en París, Sarmiento y Darío ponen en evidencia la imposibilidad de pensar la posibilidad de una modernidad latinoamericana en sí misma, como concepto aislado del modo en el que circulan socialmente los discursos sobre la modernidad al otro lado del Atlántico. Por el contario, lo que pretendo leer en la construcción que hacen de la cultura francesa y su capital es que de ella se desprende una espacialización de la teleología moderna, en la que ellos inscriben a París como centro y origen ontológicamente privilegiado y a América Latina como un margen, definido por su carencia. Para decirlo de otro modo, Sarmiento y Darío establecen (desde una perspectiva que no sería incorrecto denominar transatlántica) que la condición de posibilidad para elaborar sus deseos de modernidad es ponerlos en relación con la modernidad europea. Lúcidamente, entienden que es imposible pensar la identidad moderna a la que aspiran como una producción autóctona y pura; entienden, a la vez, que es imposible desconocer la asimetría que existe entre la hegemonía global de la modernidad europea y la marginalidad de América Latina, pero conceptualizan esa marginalidad de manera optimista, como la llave para acceder a una modernidad original, propia (Darío más que Sarmiento, y Borges más que los dos juntos). Pero, además, al partir de la condición marginal de Latinoamérica, es decir, al aceptar desde el comienzo que lo que tienen que teorizar es una modernidad marginal, y no la modernidad universal que creen ver escenificada en París, sus discursos de la modernidad se transforman es discursos de la diferencia, y de la identidad del margen. Dicho de otra manera: cuando América Latina se representa a sí misma como un margen definido por su exclusión del universal moderno, el deseo de ser moderno es elaborado a través de la pregunta por la propia identidad.

La pregunta que se desprende de este planteo es: ¿Por qué la cuestión por la identidad es constitutiva de los discursos modernos del margen y no sucede lo mismo, por ejemplo, en Europa? ¿Por qué la recurrente pregunta por nuestra modernidad supone una crisis o al menos una desestabilización de nuestra identidad? ¿Y por 
qué el proyecto de la modernidad en Europa y Estados Unidos está sostenido en el siglo xix por una identidad aparentemente estable? ${ }^{1}$

La expansion global de instituciones y prácticas burguesas a través de procesos coloniales, guerra y comercio entre los siglos xvi y xix, le aseguró a los sujetos de esa expansión una plataforma para representarse a sí mismos como sujetos universales. Si la burguesía europea imaginaba que sus particularidades sociales y psicológicas eran en verdad idénticas a la universalidad de la naturaleza humana, entonces la emergencia de la modernidad de ninguna manera podía implicar una crisis de identidad. De acuerdo con esta autorrepresentación, su subjetividad burguesa volvía a estos individuos inmediatamente, naturalmente modernos. De más está decir que la situación tenía que ser completamente diferente en los márgenes del universal, en el otro extremo del proceso de expansión, en los márgenes del universal.

La implantación de una estructura social incipientemente moderna en los márgenes del mundo, entonces, supone una crisis de identidad de difícil resolución. La construcción hegemónica de los sujetos metropolitanos como representantes de la universalidad de la iglesia y/o de la burguesía relega al "otro" y lo enfrenta a una decisión en la que se juega, a la vez, el acceso a la modernidad y a la fantasía de una identidad estable. La decisión del margen pasaría entonces por aferrarse a la universalidad moderna de Europa en un proceso de conversión que supone dejar atrás su particularidad cultural y social, o privilegiar su particularidad, recluirse en tradiciones propias que cree poder conservar en estado puro, y rechazar esa universalidad, esa modernidad, que percibe extraña y ajena. Quisiera proponer que los intelectuales más lúcidos e interesantes de América Latina han entendido que este "dilema de las modernidades marginales" presenta una opción falsa entre modernidad e identidad, y entonces conceptualizan su marginalidad como una negociación entre universalidad moderna y particularidad local. El resultado es una identidad moderna constantemente en crisis, inestable, que reclama volver constantemente sobre ella para interrogarla, para reafirmarla, reforzarla, reconstruirla.

\footnotetext{
1 Lo que me interesa del concepto de “margen” es que presenta las condiciones de enunciación, para la postulación de una identidad definida de manera contingente en función de una exclusion que siempre debe ser especificada en un contexto histórico, ético y estético determinado. En este sentido, en su pontencial identificatorio, la noción de "margen” evita cualquier forma de esencialismo geopolítico, lo cual la diferencia radicalmente de ideas como "tercer mundo" o "periferia”, conceptos que presuponen la división del mundo en totalidades "centrales" y "perifericas", bloques homogéneos que pasan por alto la complejidad que constituyen a ese "tercer mundo" internamente contradictorio (campo/ ciudad, clase, género, etc.). Con esto quiero decir que creo que el concepto de "margen", a un tiempo, permite pensar la especificidad de la diferencia latinoamericana respecto de los centros globales de la modernidad, sin volver invisibles la distribución desigual de los procesos de modernización en América Latina $y$ en los "márgenes” de las metrópolis europeas, como los disturbios que estallaron en los suburbios de París en 2005 lo prueban.
} 
Por eso, la modernidad en el margen del universal se articula a través de la pregunta por la identidad.

\section{3. 'A day at the Races': SARMiento Va AL hipóDROMO}

Sarmiento parte hacia Europa desde Chile en 1845, apenas seis meses después de la publicación de_Facundo, su primer libro, que pretendía dar cuenta, a través de la fórmula binaria “civilización/barbarie”, de la situación de la por entonces Confederación Argentina a la salida de las luchas por la independencia en las décadas de 1820 y 1830. Más allá de la especificidad de los referentes históricos argentinos, el Facundo plantea la encrucijada en la que se encuentra el contenido a la salida de los procesos de independencia: de un lado "la naturaleza campestre, colonial y bárbara”, autoritaria e irracional de América; del otro, la posibilidad de la modernización política y cultural: la civilización. En largas descripciones de la fisionomía argentina, Sarmiento explica su teoría del determinismo geográfico, desarrollado en tipologías rurales, para llegar a la conclusión de que la barbarie es la condición natural de América, y de que, entonces, debemos luchar contra nuestra naturaleza salvaje, imponiéndole formas modernas que la contengan y la encaucen. En el Facundo Sarmiento entreve, apenas sugeridas, esas formas modernas en las ciudades, especialmente en Buenos Aires (el potencial moderno de Córdoba está obstaculizado por el dominio de la iglesia). Pero más allá de apuntar a la ciudad, en el Facundo, la civilización, la modernidad, apenas está definida opositivamente; lo moderno -eso de lo que carecemos- es, en este libro, "aquello que no es barbarie".

Mi idea es que Viajes, el libro en el que Sarmiento narra en cartas su primera visita a Europa, África y Estados Unidos, especifica la noción de civilización que en el Facundo era sólo una función estructural de la barbarie. En Francia, y luego en Estados Unidos, entonces, Sarmiento encuentra el contenido histórico concreto para la modernidad latinoamericana de la que se imagina el constructor.

Como ya había adelantado, la hipótesis sobre la que pretendo trabajar es que la solución que encuentra Sarmiento, en su viaje, es la copia: una modernidad mimética para América Latina. El razonamiento de Sarmiento es más complejo de lo que podría parecer a simple vista. En Facundo, Sarmiento establecía que la geografía y el clima determinan el carácter bárbaro, violento, irracional y autoritario del hombre americano. Contra este determinismo se puede luchar imponiéndole formas políticas y culturales racionales inscriptas en una teleología emancipadora, pero estas ideas e instituciones no están disponibles en América-no podrían estarloy para eso se viaja, entonces, en busca de modelos a imitar. Piensa Sarmiento mientras camina por París: 
Las ideas y modas de Francia, sus hombres y sus novelas, son hoy el modelo y la pauta de todas las otras naciones; y empiezo a creer que esto que nos seduce por todas partes, esto que creemos imitación, no es sino aquella aspiración de la índole humana a acercarse a un tipo de perfección, que está en ella misma y se desenvuelve más o menos según las circunstancias de cada pueblo. (138-39)²

En la primera parte de la cita Sarmiento reafirma que Francia es "modelo y pauta" para las naciones en busca de la deseada modernidad. Pero más interesante es la segunda parte de este fragmento. Sarmiento naturaliza el acceso a la modernidad a través de la imitación: "esto que creemos imitación, no es sino aquella aspiración de la índole humana a acercarse a un tipo de perfección”. El acceso a la modernidad mediante la copia, dice Sarmiento, no es propio del margen, sino de la naturaleza humana. Evidentemente Sarmiento está preocupado por legitimar la operación mimética que está proponiendo, ya que la imitación denota la carencia que define al margen. En cualquier caso, Sarmiento se va a presentar como un dispositivo de mediación que va a activar la capacidad mimética de los americanos para que puedan sobreponerse a los determinismos geográficos que los condenan a la barbarie y acceder a la modernidad a través de la copia.

Pero, ¿qué es lo que hay que imitar de Francia para ser modernos? No se puede copiar el espíritu moderno porque Sarmiento (influido por la filosofía idealista) lo concibe como una esencia transhistórica. Lo que hay que imitar, dice en esta cita, son las novelas, modas e ideas de Francia; en otras palabras, sus instituciones modernas. Sarmiento no se va a limitar al estudio de la educación pública, motivación "oficial” del viaje financiado por el gobierno chileno a instancias de su amigo y futuro presidente, Manuel Montt. De hecho, no hay institución moderna a la que Sarmiento no le preste atención durante su viaje, en el rastreo de fuentes para su proyecto de modernidad mimética. Podría hacer una lista interminable de las anotaciones que Sarmiento hace sobre los avances tecnológicos, políticos o educativos de Europa y Estados Unidos. Sin embargo, decidí centrarme en una escena que me parece especialmente significativa, no sólo porque condensa los elementos de la operación mimética de Sarmiento, sino también porque se trata

\footnotetext{
2 El relato de la estadía parisina de Sarmiento es sumamente interesante, ya que no son pocos los pasajes en los cuales él mismo desestabiliza la noción de Francia como espacio de localización de lo universal con la que parte de Chile, y hasta llega a pintar a buena parte de la dirigencia política de la monarquía constitucional como excesivamente provinciana. Sin embargo, como sucede antes de su arribo a las costas francesas, en las últimas páginas del relato, en el momento de las conclusiones sobre su temporada en París, Sarmiento reestabiliza la hegemonía ideológica de su discurso y establece contudentemente que Francia es, efectivamente, el modelo que Argentina, Chile y el resto de América Latina debe imitar. Esta idea, sin embargo, va a volver a ser desestabilizada durante su estadía en Estados Unidos.
} 
de una institución donde uno no esperaría que Sarmiento encuentre claves para la modernización de América Latina; me refiero al hipódromo.

Sarmiento está a punto de concluir su estadía en París. Ya se ha entrevistado con los políticos más importantes de la monarquía constitucional, ha entrevisto los descontentos sociales que van a terminar en las revoluciones proletarias y burguesas de 1848, ha visitado a escritores, salones literarios, y hasta los bailes públicos. Pero antes de partir para España, descubre que "[h]ay otro espectáculo aún más adaptable a nuestra manera de ser, civilizador por el costado mismo que tenemos del bárbaro, por la destreza y la posesión popular del caballo” (142). Sarmiento, insospechadamente fascinado, repara en el hipódromo como una institución moderna con una función pedagógica, civilizadora:

\footnotetext{
El hipódromo es una creación nueva del espíritu parisiense, que se incorporará bien pronto en el catálogo de diversiones públicas de todas las naciones europeas, y que debiera ser transportado incontinenti a América, en donde echaría raíces profundas, como todo lo que es eminentemente popular.... El hipódromo presenta todas las aptitudes del caballo, y cuanto hay de noble y de artístico en el hombre para dominarlo y dirigirlo. Nuestros gauchos y nuestros guasos son insignes equitadores... pero fáltanos a nosotros arte, esto es, el arte antiguo, las posiciones nobles de la estatuaria, el estudio de las fuerzas, y la gracia y gentileza de las clases cultas. Con nuestro poder de guasos sobre el caballo y el arte europeo, el hipódromo sería en América una diversión popular y una alta escuela de cultura. $(142-43)$
}

La cita da cuenta del potencial modernizador inclusivo que el hipódromo puede tener en relación con los gauchos -quienes, después de la caída de Rosas en 1852, van a ser considerados los últimos sujetos marginales potencialmente redimibles; los gobiernos de Mitre y Sarmiento van a desarrollar políticas públicas para propiciar su incorporación forzosa al ejército nacional a través de la institución de la leva; otros sujetos marginales como el indio, en cambio, van a ser considerados irrecuperables, irredimibles y, entonces, masacrados. De acuerdo con la observación de Sarmiento, la imitación del hipódromo es un ejemplo perfecto de su voluntad de imponer formas culturales sobre las particularidades culturales populares (es decir, premodernas) que él consideraba bárbaras, como la destreza hípica. Instituciones como el hipódromo serían capaces de sobreimprimir subjetividades modernas, culturales, en la superficie de la identidad bárbara determinada por una naturaleza desbordada e informe. Es decir, a diferencia de otras instituciones potencialmente imitables, el hipódromo sería capaz de lograr al mismo tiempo un efecto universalizador/modernizador, recuperando elementos particulares de las prácticas culturales latinoamericanas que Sarmiento identifica con la destreza 
hípica. En otras palabras, para Sarmiento, el hipódromo, desde su universalidad moderna, interpela a la particularidad latinoamericana.

Pero, ¿cuántas instituciones como el hipódromo encuentra Sarmiento en sus viajes, capaces de producir sujetos modernos en los que la universalidad de la razón y la particularidad de la cultura local estén tan perfectamente reconciliados? Ninguna otra. El hipódromo es la excepción dentro del conjunto de instituciones modernas que Sarmiento propone imitar. Y es que Sarmiento está más interesado en acceder a la modernidad, inscribirse en el arrollador progreso de la historia universal, que en preservar la diferencia cultural latinoamericana que corre el riesgo de perderse en el camino de una modernización desenfrenada. Frente al dilema de las modernidades marginales que describí anteriormente, Sarmiento se aferra al universal hegemónico de Europa y Estados Unidos, aún a costa de resignar la especificidad latinoamericana. El resultado es una modernidad mimética una modernidad de segundo grado, donde la marginalidad no depara una modernidad diferente, sino una modernidad degradada. De todos modos, piensa Sarmiento desde el interior de su lógica binaria y disyuntiva, siempre es mejor ser una copia aún imperfecta de la universalidad europea y/o norteamericana que resignarse a constituirse en un Otro irreconciliable de la modernidad, en la particularidad radical de la barbarie rosista.

Sobre el final de su estadía en Francia, Sarmiento le dice a su corresponsal chileno que para él los hombres civilizados de Chile y América no son chilenos, sino europeos en América: "Pero en Chile (equivocadamente) empiezan a creer hombres muy serios, que el chileno es chileno y no europeo" (143). Así, finalmente, Sarmiento revela la voluntad utópica inscripta en el corazón de su proyecto de modernidad mimética: transformar a América Latina en una Europa desplazada; la construcción de la América europea con la que soñaban los adelantados que creían encontrar la redención del viejo mundo en cada Nueva España, Nueva Granada, New England que fundaban. Y sobre todo, la identidad que resulta de su modernidad mimética de ninguna manera tiene la estabilidad que él proyectó sobre la subjetividad moderna de Francia. No se trata de una identidad universal y particular, moderna $y$ latinoamericana, como hubiese resultado de seguir el modelo del hipódromo, sino de un sujeto quebrado, porque no sería europeo (no podría serlo por el principio básico de no-identidad, "si a = a, no es igual a b”), y tampoco habría preservado su particularidad latinoamericana, perdida en el proceso de copiar la universalidad moderna que habría de conseguir sólo en una forma degradada.

Es este el contexto en el que la intervención de Darío será crucial. 


\section{DARÍO: TRADUCIR LA MODERNIDAD}

El modernismo, o mejor, la articulación que hace Rubén Darío del discurso del modernismo y el proyecto de una modernidad latinoamericana, supone una ruptura radical respecto del modo en el que los intelectuales latinoamericanos pensaban hasta ese momento la posibilidad de construir una identidad moderna para la región. Este quiebre que se da hacia el fin de siglo (y que quizás podría localizarse alrededor de 1896, año en que fueron publicados sucesivamente Los raros y Prosas profanas) se da en relación con el paradigma hegemónico que había encarnado Sarmiento, y que, tras su muerte, perpetuaban figuras interesantes y complejas como Paul Groussac.

Groussac, que había llegado a la Argentina desde su Francia natal en 1866 con 18 años, era ya durante la década de 1890 lo que Bourdieu llama un intelectual faro, alrededor de quien se estructuraba el campo intelectual argentino de fin de siglo. Inmediatamente después de la publicación de los dos libros de Darío en 1896, Groussac los reseña en la revista de la que era editor, La Biblioteca, de manera muy crítica. Acusa a Darío de ser un imitador trivial de los simbolistas y decadentes franceses, y concluye su reseña con una cita de Copée en la que le pregunta irónica y cínicamente a Darío si puede haber algún tipo de originalidad en la copia y el plagio. Darío le responde desde las páginas del periódico La Nación con un artículo, "Los colores del estandarte", que llegó a tener el estatuto de manifiesto que se les otorga a las "Palabras liminares" de Prosas profanas y al "Prefacio" de Cantos de vida y esperanza. Darío escribe que

pensando en francés y escribiendo en castellano... publiqué el pequeño libro que iniciaría el actual movimiento literario Americano... el Azul es un libro parnasiano, y por lo tanto, francés. En él aparecen por primera vez en nuestra lengua, el "cuento" parisiense, la adjetivación francesa, el giro galo injertado en el párrafo castellano... Qui pourrais-je imiter pour être original? me decía yo. Pues a todos. A cada cual le aprendía lo que me agradaba, lo que cuadraba a mi sed de novedad y a mi delirio de manifestación individual. Y el caso es que resulté original. (162-63)

Darío toma la acusación de Groussac y el proyecto modernizador sarmientino que él encarna y lo pone patas para arriba para reivindicarlo como propio. Si Sarmiento concebía la copia literal como condición de posibilidad de la modernidad en el margen, Darío va a decir: de acuerdo, no tenemos más remedio que recurrir a la imitación, en función de un doble reconocimiento: 1) reconocimiento de la hegemonía de Francia en la espacialidad moderna, y 2) reconocimiento de la marginaliad de América Latina, donde, consecuentemente, la originalidad pura 
está vedada. Darío concuerda con Sarmiento respecto del privilegio ontológico de Francia, pero no se resigna a que la única posibilidad disponible para el margen sea una modernidad europea en América Latina. El reconocimiento de la marginalidad latinoamericana le permite a Darío resignificar la idea sarmientina de imitación y transformarla en una apropriación, o mejor, en una imitación creativa, y todavía mejor, como traducción. Mi idea es que Darío toma la idea de imitación literal de Sarmiento, para pensarla en términos de traducción, pero no traducción en el sentido convencional del término, como pasaje más o menos transparente de una lengua a la otra; traducción en el sentido que Borges le da al concepto en "Los traductores de las 1001 noches” y en “Las versiones homéricas”: traducción como práctica que reconoce una opacidad impenetrable entre lenguas y contextos culturales, y entonces adquiere la forma de una reescritura.

Quiero proponer que es en este desplazamiento del sentido de la imitación -de la mímesis a la traducción como apropiación creativa- donde pueden encontrarse las claves para pensar el proyecto de Darío de una modernidad particularmente latinoamericana y no ya una modernidad europea en América. Voy a leer esta operación en un poema excéntrico, que problematiza y pone en escena la dislocación de la idea de Francia como modelo que es central para la modernidad mimética de Sarmiento. El poema, que se llama "France-Amérique” (publicado en Canto a la Argentina y otros poemas), está escrito en francés y ya desde el título sugiere que una identidad marginal moderna depende de la resignificación de las ideas sarmientinas sobre la relación con Francia como referente de la modernidad, para poder pensar en la posibilidad de una modernidad propia, producida mediante un proceso de traducción. Cito apenas dos estrofas:

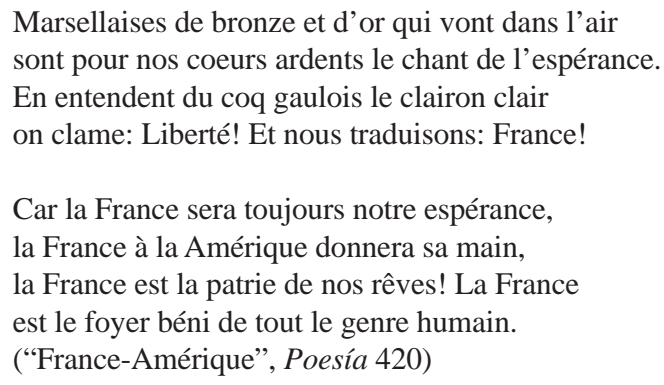

El primer paso para una interpretación del poema, me parece, es dejar de lado todo lugar común que atribuya la escritura del poema en francés al afrancesamiento, al “galicismo mental” de Darío. Traducir Francia no sólo es el tema central del poema, sino que es también la condición de posibilidad del acceso al texto. Pero es 
necesario llegar al fondo del sentido que tiene la traducción en este poema y en el discurso moderno de Darío. Veamos: si Francia es el emblema de una modernidad que realiza el sueño de la libertad universal para toda la humanidad, para poder inscribirse en el interior de ese proyecto hay que efectuar una doble traducción de los versos "En entendent du coq gaulois le clairon clair/ on clame: Liberté! Et nous traduisons: France!”. Por un lado, el hecho de que Darío pone de relevancia la necesidad de traducir el grito de libertad pone en evidencia que la identificación de los significantes “France” y “Liberté” es el resultado de una construcción de Darío desde América Latina y para América Latina. Darío parece decir: somos nosotros, en función del complejo edificio moderno que estamos tratando de erigir desde América Latina, para América Latina, los que establecemos la equivalencia lingüística entre el proyecto libertario de la modernidad y Francia. En otras palabras, hay una especificidad latinoamericana o si se quiere, marginal en esta traducción. Para mostrar que la traducción de Darío es específica, particularmente latinoamericana, basta confrontarla con otros contextos. Esta traducción sería impensable, por ejemplo, desde Estados Unidos, en 1911, con la expansión colonial norteamericana en full swing y la doctrina de la excepcionalidad y el destino manifiesto en su apogeo. En cualquier caso, el poema pone en evidencia que la construcción de una identidad moderna para América ya no puede ser articulada por un concepto de imitación literal que concibe la transición transatlántica en términos de transparencia. Por el contrario, la idea de traducción que Darío coloca en el centro de este proceso pone en evidencia la artificialidad de un traslado mimético; en otras palabras, si el contexto de producción de la modernidad latinoamericana es la opacidad que separa a las culturas hegemónicas y marginales, entonces la relación que las segundas deberán establecer con las primeras tendrá que ser creativa.

“¿Aquién puedo imitar para ser original?”, se preguntaba Darío en “Los colores del estandarte”, y esta pregunta reclama ser traducida: ¿a quién debo imitar/traducir para ser moderno en mis propios términos? La clave de la modernidad traducida de Darío es inscribirnos en la universalidad moderna que encarna Francia, pero también inscribir a Francia en nuestro propio ser cultural a través de su traducción a nuestras propias condiciones culturales: "Azul es un libro parnasiano, y por lo tanto, francés”, escribe Darío en "Los colores del estandarte” (162). En América Latina, ser moderno es ser francés en la manera que Azul es un libro francés; es decir, entonando lo francés, lo moderno, en nuestro castellano: “pensando en francés y escribiendo en castellano” (“Los colores del estandarte”, 162), así dice Darío que escribió Azul, y podría extenderse la hipótesis a la totalidad de su escritura. Darío revisa el principio mimético de Sarmiento, que aspiraba a ser literalmente francés en América. Para Darío podemos ser franceses/modernos, traduciéndolos; pero no se trata de traducir Francia, sino el atributo que la vuelve moderna, su universalidad. Si 
los franceses son modernos de manera natural e inmediata, el margen será moderno de manera mediada, traducida. Vivir en el margen supone vivir traduciendo en términos de su particularidad cultural e histórica lo que se presenta a priori como universal; la traducción determina el ser cultural del margen.

La traducción, entonces, es la solución de Darío al “dilema de las modernidades marginales": ser modernos como Europa. No se trata ya, como en Sarmiento, de ser Europa. La operación de traducción creativa y apropiación de Darío, al fin y al cabo un poeta, se vuelve visible en la presencia retórica del como; establecer una relación metafórica con Europa, ser modernos sin dejar de ser latinoamericanos, ser universales por traducir la modernidad a nuestra particularidad; apropiarnos de la modernidad o, parafraseando las "Palabras liminares" de Prosas profanas, volver a la modernidad nuestra en nosotros. ${ }^{3}$

\section{CodA BORgEANA.}

Para concluir, quisiera sugerir brevemente, muy brevemente, cómo podrían seguir pensándose estas hipótesis en el siglo xx, en un contexto completamente diferente, frente a la imposibilidad de sostener el privilegio ontológico de la cultura europea. En otras palabras, me interesa leer qué pasa con la conceptualización de las modernidades marginales cuando ya no puede pensarse en Europa, Estados Unidos u Occidente como culturas inmediata y naturalmente universales en sí mismas. Me interesa ver este quiebre con el esencialismo, constitutivo de Sarmiento y todavía presente en alguna medida en Darío, en un pasaje famoso del ensayo clave de Borges “El escritor argentino y la tradición”, escrito como una conferencia en 1951.Aquí, me parece, puede leerse una denuncia de la supuesta universalidad de la cultura europea y occidental como una construcción hegemónica, históricamente determinada, como condición de posibilidad para pensar una modernidad latinoamericana:

¿Cuál es la tradición argentina? Creo que podemos contestar fácilmente y que no hay problema en esta pregunta. Creo que nuestra tradición es toda la cultura occidental, y creo también que tenemos derecho a esa tradición, mayor que el que pueden tener los habitantes de una u otra nación occidental [...] Por eso repito que no debemos temer y que debemos pensar que nuestro patrimonio es el universo, ensayar todos

\footnotetext{
3 Reescribo y parafraseo la famosa sentencia de Darío en las “Palabras liminares” de Prosas profanas: "mi literatura es mía en mí”. Vale la pena citar el párrafo completo en el que se encuentra esta famosa declaración de principios estéticos de Darío porque reafirma su voluntad de redefinir la relación de América Latina y Europa, más allá del concepto de imitación: "Yo no tengo literatura 'mía' -como lo ha manifestado una magistral autoridad-, para marcar el rumbo de los demás: mi literatura es mía en mí; quien siga servilmente mis huellas perderá su tesoro personal y, paje o esclavo, no podrá ocultar sello o librea. Wagner a Augusta Holmes, su discípula, dijo un día: 'Lo primero, no imitar a nadie, y sobre todo, a mí'. Gran decir”.
} 
los temas y no podemos concretarnos a lo argentino para ser argentinos: porque 0 ser argentino es una fatalidad y en ese caso lo seremos de cualquier modo, o ser argentino es una mera afectación, una mascara. $(272,274)$

La propuesta de Borges es tomar por asalto la cultura occidental, apropiarse irreverentemente de ella. Explícitamente afirma que lo específicamente argentino es la cultura universal; o para decirlo de otro modo: la particularidad argentina y la universalidad de lo moderno se superponen, y hasta podríamos decir que son exactamente lo mismo. Borges borra el límite que separa y diferencia a lo universal de lo particular. Radicalizando la operación de Darío, Borges universaliza lo particular, y particulariza lo universal, hasta dejar claro que es indistinto hablar de uno u otro.

Con esta desconstrucción de la relación jerárquica entre lo universal y lo particular, Borges ataca dos tipos de esencialismos. Por un lado, contra determinismos y nacionalismos (por dentro y por fuera de la hegemonía del peronismo, que constituye el primer contexto de la escritura del ensayo), Borges presenta la idea de una identidad socialmente construida, como afectación y máscara. Por el otro, ataca la idea de que la cultura occidental y la europea comparten una universalidad a priori, relegando a América Latina al rincón de las particularidades localistas e irredimibles. Me gustaría derivar dos conclusiones implícitas en estas ideas de Borges. Primero, la denuncia implícita de la identificación de la particularidad cultural de Europa con la universalidad moderna de la cultura occidental como una construcción hegemónica. En este sentido, Ernesto Laclau explica que lo universal no existe como tal, sino que resultado de un proceso hegemónico según el cual una cultura representa su particularidad en términos universales: "The universal has no necessary body and no necessary content; different groups, instead, compete between themselves to temporarily give to their particuralisms a function of universal representation”(35). Es precisamente a partir del quiebre que posibilita esta denuncia de la hegemonía eurocéntrica, que asume la representación de la universalidad de la modernidad en la materialidad de su propia particularidad, que Borges encuentra el espacio de enunciación para formular la línea más provocativa de su ensayo: “Creo que nuestra tradición es toda la cultura occidental, y creo también que tenemos derecho a esa tradición, mayor que el que pueden tener los habitantes de una u otra nación occidental”. Tenemos tanto o más derecho que Europa a la universalidad de la cultura occidental -dice Borges- porque esa universalidad es contingente y depende de una construcción política que de ninguna manera nos está vedada. Debemos construir nuestra identidad cultural en función de disputarle el monopolio sobre la cultura occidental a aquellas naciones que se piensan a sí mismas idénticas con la tradición universal y nos relegan a sus márgenes. 
Esto me lleva a la segunda conclusión que querría sacar. Quisiera leer en la subversiva idea de que el margen puede ser moderno apropiándose de la cultura occidental no un intento de universalización de América Latina, sino la desuniversalización de la cultura occidental; mostrar que sólo existen culturas particulares que ocupan espacios hegemónicos y subalternos en construcciones políticas concretas. En otras palabras, no se trataría de invertir el modelo estancado y determinista de Sarmiento, sino de radicalizar la operación de Darío: comprender que el universal no tiene una localidad fija, que se lo puede encontrar tanto en el Faubourg Saint-Germain como en un Aleph azarosamente hallado en el sótano de una casa en la calle Garay de la ciudad de Buenos Aires.

\section{BiBLIOGRAFÍA}

Borges, Jorge Luis. "El escritor argentino y la tradición”. Discusión. Obras Completas. Buenos Aires: Emecé, 1974.

Darío, Rubén. "France-Amérique”. Poesía. Ernesto Mejía Sánchez, Angel Rama y Julio Valle-Castillo, eds. Caracas: Biblioteca Ayacucho, 1977.

"Los colores del estandarte". Nosotros. Revista de letras, arte, historia, filosofía y ciencias sociales (febrero de 1916).

"Palabras liminares". Prosas profanas y otros poemas. José Ovidio Jiménez, ed. Madrid: Alianza, 1992.

Autobiografía. Madrid: Mondadori, 1990.

Laclau, Ernesto. Emancipations. Londres: Verso, 1996.

Sarmiento, Domingo F. Facundo, o civilización y barbarie. Noé Jitrik, ed. Caracas: Biblioteca Ayacucho, 1977.

Viajes en Europa, Africa y América. Buenos Aires: Editorial de Belgrano, 1981. 